\title{
[Erratum] Effect of Addition of ESCM and ESM during In Vitro Maturation on In Vitro Development of Porcine Follicular Oocytes
}

\author{
Seok-Gi Kim ${ }^{1,2, *}$ and Hum-Dai Park ${ }^{1}$
}

${ }^{1}$ Department of Biotechnology, College of Engineering, Daegu University, Gyeongsan 38453, Korea

${ }^{2}$ IVF Center, Mamapapa and Baby Clinic, Ulsan 44707, Korea

J Anim Reprod Biotechnol 2019;34:205-211

https://doi.org/10.12750/JARB.34.3.205

This correction is being published to correct the corresponding author in above article.

\section{Before Correction}

\section{Seok-Gi Kim ${ }^{1,2, *}$ and Hum-Dai Park ${ }^{1}$}

${ }^{1}$ Department of Biotechnology, College of Engineering, Daegu University, Gyeongsan 38453, Korea ${ }^{2}$ IVF Center, Mamapapa and Baby Clinic, Ulsan 44707, Korea

\author{
*Correspondence \\ Seok-Gi Kim \\ E-mail: s2k3kim@hanmail.net \\ ORCID \\ https://orcid.org/0000-0002-5893-5920
}

\section{After Correction}

Seok-Gi Kim ${ }^{1,2}$ and Hum-Dai Park ${ }^{1, *}$

${ }^{1}$ Department of Biotechnology, College of Engineering, Daegu University, Gyeongsan 38453, Korea

${ }^{2}$ IVF Center, Mamapapa and Baby Clinic, Ulsan 44707, Korea

*Correspondence

Hum-Dai Park

E-mail: humdai@daegu.ac.kr

ORCID

https://orcid.org/0000-0002-3721-9167 